\title{
Quantitative analysis of survivin in colorectal adenocarcinoma: increased expression and correlation with telomerase activity
}

Running title: survivin in colorectal cancer

Alfred King-Yin Lam, MBBS, PhD, MD, FRCPA ${ }^{1}$

Said Saleh, BSc, $\mathrm{PhD}^{2}$

Robert Anthony Smith, BSc, $\mathrm{PhD}^{1}$

Yik-Hong Ho, MBBS, MD, FRACS²

${ }^{1}$ Discipline of Pathology, Griffith Medical School, Medicine and Oral Health Centre, Gold Coast Campus, Gold Coast, Queensland 4222, Australia

${ }^{2}$ Discipline of Surgery (School of Medicine) and North Queensland Centre for Cancer

Research (Australian Institute of Tropical Medicine), James Cook University,

Townsville, Queensland 4811, Australia

Correspondence and/or reprint requests:

Professor Alfred Lam

Head of Pathology, Griffith Medical School

Gold Coast Campus

Gold Coast QLD 4222

Australia

Phone +61 7 56780718; Fax +61 7 56780708; E-mail: a.lam@griffith.edu.au

KEYWORDS: survivin, telomerase, colorectal adenocarcinoma 


\section{ABSTRACT}

The aims of the present study are to quantitatively analyse survivin expression, its clinicopathological roles and correlation with telomerase activity in a large cohort of patients with colorectal adenocarcinoma. Real-time polymerase chain reaction was used to quantitate expression level of survivin mRNA and hTERT mRNA (telomerase activity) in 51 patients with colorectal adenocarcinomas. The findings were correlated with the clinicopathological features of patients which were prospectively collected into a computerized database. Survivin mRNA was expressed in all tumour samples. The level of expression in tumour tissues was increased in comparison with matched non-tumour mucosa in the same patient $(\mathrm{p}=0.01)$. The level of expression of survivin was significantly correlated with the level of hTERT expression $(p=0.008)$ and size of the colorectal adenocarcinomas ( $\mathrm{p}=0.004)$. Survival of the patients with colorectal adenocarcinoma was associated with the TNM stages $(p=0.001)$ and not with the level of expression of survivin. Thus, survivin activity was altered in colorectal adenocarcinoma. The high prevalence of survivin expression and correlation with telomerase activity are important factors for consideration in gene targeting therapy for colorectal adenocarcinoma. 


\section{INTRODUCTION}

Colorectal cancer ranks high in incidence and mortality among malignancies in the Western world [1]. Research contributes directly to improve the care of patients with colorectal cancer by more accurately refining prognosis and selecting the most appropriate adjuvant therapy for individual patients with colorectal cancer [2]. In recent years, studies into the molecular pathways involved in cancer growth have allowed identification of genes like survivin and telomerase [3]. These genes have attracted growing attention as they are potential targets for cancer treatment.

Human telomerase is a ribonucloprotein composed of two components, human telomerase RNA (hTR) and human telomerase reverse transcriptase (hTERT) [4,5]. It is a cellular reverse transcriptase that helps maintain telomere length in human stem cells, reproductive cells and cancer cells by adding TTAGGG repeats onto the telomeres at the end of the chromosomes. Telomerase activity has been found in more than $85 \%$ of all human tumours, as well as germ and stem cells $[6,7]$. In our previous study, we documented that telomerase activity was increased in colorectal adenocarcinoma when compared to adenoma and non-tumour mucosa [8]. The expression was higher in adenocarcinomas arising from distal portion of the colorectum.

Survivin, a member of the inhibitor of apoptosis protein family, is a recently discovered protein which plays a key role in regulation of apoptosis and cell division [9,10]. It is a $16.3 \mathrm{kD}$ protein consisting of 142 amino acids. The gene encoding survivin is located at the telomeric region of the chromosome 17. Survivin is abundantly expressed in fetal tissues, yet undetectable in most normal, terminally differentiated adult tissues. It is overexpressed in a variety of cancers [11]. Normal human cell do not require survivin for survival, which would make survivin an advantageous target for 
treatment of cancer [12]. The roles of survivin have not been studied in depth in colorectal cancer. Although survivin activity has been detected in colorectal cancer by immunohistochemistry, quantitative analysis of survivin has seldom been performed [1328]. In addition, the interaction of survivin expression with telomerase activity and clinical and pathological factors has also rarely been investigated [15].

In this study, we evaluated the expression level of survivin mRNA in tumour tissues and corresponding adjacent non-tumour mucosa from patients with colorectal adenocarcinomas by using real-time reverse transcriptase polymerase chain reaction. We also analyzed the relationship between survivin expression, hTERT expression level and clinicopathological features of the patients. 


\section{MATERIALS AND METHODS}

\section{Patients and tissue recruitment}

Fifty-one consecutive patients (32 men, 19 women) with confirmed primary colorectal adenocarcinoma were recruited. Consent for the study was obtained from each of the patients and hospital human ethics committee. The age, gender, clinical management and survival data of these patients were prospectively collected in a computerized database. The actuarial survival rate of the patients was calculated from the date of surgical resection of the colorectal carcinomas to the date of death or last follow-up. Management was by a pre-agreed standardized multidisciplinary protocol supervised by a senior specialist colorectal surgeon. None of the rectal cancer patients had undergone neoadjuvant radiotherapy or chemotherapy prior to surgery. Pathological diagnosis was also standardized and reviewed by committee criteria, chaired by a senior academic pathologist with a special interest in the field. Post-operative chemotherapy was given to patients with stage III colon cancer whereas post-operative chemoradiation was given to patients with stage III rectal cancer. Follow-up was routinely performed at three monthly intervals for the first two years, six monthly for the subsequent three years, and yearly thereafter. Serum carcino-embryonic antigen (CEA) levels were taken before each visit and imaging investigations performed as clinically appropriate. Colonoscopy was performed at one year after surgery, and repeated as appropriate to the findings and other clinical features at follow-up.

The tissue samples were collected prospectively. The site and size (maximum length) of the colorectal cancers were recorded. At the time of surgery, the tissue from the tumour and non-tumourous colorectal mucosa from the proximal resection margin were promptly sampled. These samples were preserved in RNAlater within 10 minutes 
of surgery to prevent degradation of the RNA and then stored at $-80{ }^{0} \mathrm{C}$. Standard blocks were then taken, fixed in $10 \%$ formalin and embedded in paraffin wax. Histological sections were cut from the paraffin embedded blocks and stained for hematoxylin and eosin for light microscopic examination. The histological subtypes were classified using the World Health Organization (WHO) criteria [29]. Mucinous adenocarcinoma was defined as an adenocarcinoma with more than $50 \%$ of the tumour composing of extracellular mucin. The carcinomas were staged according to TNM (Tumour, Lymph node and Metastases) classification adopted in American Joint Committee on Cancer [30].

\section{Laboratory procedures}

\section{$\underline{\text { RNA extraction }}$}

Total RNA was extracted from the 10-25 mg of fresh frozen tissue by disruption and homogenization using High Pure RNA Tissue Kit (Roche Diagnostics, Mannheim, Germany). DNase I was used to digest DNA contamination. Quality of the RNA was checked by agarose gel electrophoresis to rule out degraded RNA.

\section{cDNA preparation}

Purified total RNA was reverse transcribed in a total volume of $25 \mu \mathrm{l}$ using random primer at a ratio 2 to 1 RNA and transcriptor reverse transcriptase (Roche Diagnostics, Mannheim, Germany). The reaction mixture was incubated for 10 minutes at $25{ }^{0} \mathrm{C}$ first, 60 minutes at $50{ }^{\circ} \mathrm{C}$, and followed by enzyme inactivation step for 5

minutes at $85{ }^{0} \mathrm{C}$. The cDNA samples were stored at $-20{ }^{\circ} \mathrm{C}$ until use. 


\section{$\underline{\text { Real time quantification PCR }}$}

Rotor gene system (Corbett Research, Sydney, Australia) was used to run realtime quantification polymerase chain reaction. Absolute quantification assay was chosen to analyze hTERT (target), survivin (target), and glyceraldehydes 3-phosphate dehydrogenase (GAPDH, endogenous control) genes expression. PCR was performed in a total volume of $20 \mu$ reaction mixture containing $1 x$ TaqMan universal master mix with AmpErase uracil N-glycosylase (Applied Biosystems, Foster City, USA)(to prevent the re-amplification of carry-over PCR products), 600nM of each primer, 200nM TaqMan probe, and $1 \mu \mathrm{l}$ of unknown cDNA or $2 \mu \mathrm{l}$ of standard template. All the samples (unknown and standard) were run in duplicate and accompany with non- template control. Thermal cycling conditions included $2 \mathrm{~min}$ at $50{ }^{\circ} \mathrm{C}$ and $10 \mathrm{~min}$ at $95{ }^{\circ} \mathrm{C}$, followed by 45 cycles at $95{ }^{\circ} \mathrm{C}$ for $15 \mathrm{sec}$ and $60{ }^{\circ} \mathrm{C}$ for $60 \mathrm{~min}$.

\section{Primers and probes}

The primer set and probe for amplification of hTERT (GenBank accession number AF015950), survivin (GeneBank accession number NM_001168), and GAPDH, (GenBank accession number NM_002046) genes were designed using GenScript web site/design tool (www.genscript.com/ssl-bin/app/primer). The primers for the genes placed in different exons, were checked by conventional PCR to ensure they did not amplify genomic DNA. The probes contained 6-carboxyflourscein (FAM) as fluorescent reporter dye, and 6-carboxytetramethyl-rhodamine (TAMRA) as quencher for its light emission spectrum. These probes were purchased from Sigma Genosys (Wollands, TX, USA). During the extension phase of PCR, the probe hybridized to the target sequence and was then cleaved due to the 5' to 3' exonuclease activity of Taq polymerase. The 
increase in fluorescence signal of the reporter was proportional to the amount of specific PCR products, providing highly accurate and reproducible quantification.

\section{$\underline{\text { Standard curve }}$}

For absolute quantitation assay, a standard curve was constructed from a known concentration of DNA sample. A segment of 290 bp hTERT gene was generated by conventional RT-PCR. The PCR-product was checked on agarose gel for unspecific amplification, purified by High Pure PCR Product Kit (Roche Diagnostics, Mannheim, Germany), and then accurately quantified by ultraviolet-spectrophotometer. The concentration of known DNA sample was converted to molecules per microliter. This known standard sample was adjusted to $0.8 \times 10^{10}$ molecule/ $\mu \mathrm{l}$ and then serially diluted by 1/10 down to $6 / \mathrm{ul}$. Two $\mu \mathrm{l}$ of each dilution $\left(10^{6}\right.$ to $\left.10^{1}\right)$ in duplicate was used as a template for real time PCR. For each sample, the expression level of hTERT, survivin, and GAPDH were quantified as a copy numbers (per reaction) using the standard curve. Expression level of hTERT and survivin for each sample was normalized by dividing to the copy number of GAPDH (Normalization = copy number of target gene sample $_{\text {/ }}$ copy number of GAPDH sample $\mathrm{x} 100)$.

\section{Statistical analysis}

Comparisons between groups were performed using the chi-square test, Fisher's exact test and student t-test. Fisher's exact test or likelihood ratio was used for categorical variables. Student t-test with Yates correction was used for continuous variables. Correlations between continuous variables were done using Pearson correlation. The significance of various parameters on survival was analyzed by the Kaplan-Meier method 
with log-rank test and multivariate Cox's regression. Significance level was taken at $\mathrm{p}<0.05$. All statistical tests were performed with the program, Statistical Package for Social Sciences (SPSS version 14.0, Chicago, IL). 


\section{Results}

The median age of the patients with colorectal adenocarcinoma was 68 (range, 37 to 89 ) years. The median age for male patients was 67 whereas for female patients was 70. The mean diameter of the tumours was $5.1 \mathrm{~cm}$ (range, 0.7 to $10.1 \mathrm{~cm}$ ). One third of the lesions were in the proximal portion of the large intestine (caecum, ascending colon and transverse colon). The other two thirds of the carcinomas were noted in the distal portion of the large intestine (descending colon, sigmoid colon and rectum). Overall, the adenocarcinomas were well-differentiated in $10 \%(n=10)$, moderately-differentiated in $78 \%(n=78)$ and poorly-differentiated in $12 \%(n=6)$. Ten per cent of the tumours were mucinous adenocarcinoma. The adenocarcinomas as classified according to TNM stages were: stage I in 18\% ( $n=9)$, II in 45\% ( $n=23)$, III in $25 \%(n=13)$ and IV in $12 \%(n=6)$.

Survivin mRNA was expressed in all tumour samples. The level of expression in tumour tissues was statistically significant $(\mathrm{P}=0.0001)$ in comparison with matched nontumour mucosa in the same patient (Figure 1). The range of the survivin mRNA expression ratio was 1.9 - 7.9 (mean, 5.2) in colorectal adenocarcinoma and 0.2 to 2.6 (mean, 1.3) in adjacent mucosa samples. All cancer samples were found to express higher survivin mRNA than the matched non-tumourous mucosa. All except 2 cancers had survivin mRNA level higher than 2.6 (the maximum expression ratio of nontumourous mucosa). The level of survivin in this population was found to have no relationship with the age and gender of the patient, grades, mucinous differentiation, sites and staging of the tumours. The level of survivin mRNA was associated with the size of the tumour $(p=0.004)$.

hTERT mRNA was expressed in all tumour samples. The range of the hTERT mRNA expression ratio in the tumours was $0.11-2.75$ (mean, 1.1) whereas the range in 
the non-tumour tissue was 0 to 1.14 (mean, 0.47 ). The level of expression of survivin was significantly correlated with the level of hTERT expression $(p=0.008)$.

\section{Survival analysis}

Follow-up data was available for all patients. According to Kaplan-Meier logrank survival and Cox-multivariate analysis, survival of the patients with colorectal adenocarcinoma was only associated with the TNM stages of the tumours $(p=0.01$ and 0.003 respectively). Patients with higher level of expression of survivin (copy number > 5) appear to have poorer survival than other patients (Figure 2). One third of the patients (9 of 27) in the former group died whereas 12.5\% (3 of 24) in the latter group died during the study period. Nevertheless, the difference between these groups did not reach significant levels $(\mathrm{p}>0.05)$. 


\section{DISCUSSION}

The current study noted that colorectal cancer tissue had a much higher survivin level than morphological non-tumour tissue. When compared to telomerase expression, survivin expression had minimal or practically no overlap in level of mRNA between cancer tissue and morphological normal tissue. In other studies, survivin is also barely detectable in terminally differentiated normal cells/tissues [13-28]. In this study, we also demonstrated for the first time that the level of survivin is related to the size of the colorectal cancer. Thus, quantitative analysis of survivin may act as a diagnostic marker in colorectal adenocarcinoma. Recently, antibodies to survivin protein have been demonstrated in the sera of patients with colorectal cancer and other cancers [31].

The only study that addressed the relationship between telomerase activity and survivin in colon cancer was from Enoh and colleages in Japan [15]. The authors indicated that survivin assists cancer cell to escape replicative senescence via enhancing telomerse activity. In this study, we confirmed that elevated expression of survivin was related to elevated expression of telomerase in fifty-one colorectal adenocarcinomas. Many telomerase and survivin inhibitors have been developed and are in the preclinical or other stages of clinical trial [3]. The findings in this study suggest that synergistic effects may occur if drugs targeting both survivin and telomerase are used.

In the literature, survivin expression was demonstrated in colorectal cancer most often by immunohistochemical method. The positive rate ranges from 40 to $78 \%$ [1626]. On the other hand, quantitative analysis by real-time PCR had been performed in studies from 2 centres [13-15].

The correlations of survivin with clinicopatholgical parameters have only been examined in a few studies. Tan and colleagues suggested some correlations between 
survivin expression and differentiation, lymph nodal status and stage of the colorectal cancer whereas Gerlach and colleagues showed that survivin expression increased with differentiation of the cancer $[13,19]$. Other than these, the other studies failed to show any relationship between survivin expression and clinicopathological parameters $[20,21,23,26,28]$. In this study, we also did not find any relationship between survivin expression and the differentiation, histological subtype, site of the tumour, age or gender of patients. Furthermore, survivin expression was linked with poorer patient survival in colorectal cancer in a few reports $[20,21,26]$. In our study, higher levels of survivin expression were associated with poorer survival. However, the difference did not reach statistical significance.

In conclusion, the role of survivin was studied in a large cohort of patients with colorectal adenocarcinomas. Survivin expression was significantly increased in cancer and associated with telomerase activity and size of the tumour. The findings imply that survivin is important in the pathogenesis of colorectal adenocarcinoma. Also, high level of survivin expression is a potential biomarker for colorectal cancer and a potential indicator for good candidate for gene targeting therapy to the cancer. The high level of survivin expression and correlation with telomerase activity may be important for consideration of gene targeting therapies for colorectal cancer. 


\section{ACKNOWLEDGMENTS -COMPETING INTERESTS - FUNDING}

\section{Acknowledgements:}

The authors would like to thank the staff in Pathology Queensland in providing access to slides and blocks for the study. The first two authors contributed equally to the work

\section{$\underline{\text { Source of support }}$}

The project was supported by a grant from the Queensland Cancer Fund. 


\section{REFERENCES}

1. Parkin DM, Bray F, Ferlay J, Pisani P. Global cancer statistics 2002. CA Cancer J Clin 2005; 55:74-108.

2. Alvarado MD, Jensen EH, Yeatman TJ. The potential role of gene expression in the management of primary and metastatic colorectal cancer. Cancer Control. 2006;13:27-31.

3. Zaffaroni N, Pennati M, Folini M. Validation of telomerase and survivin as anticancer therapeutic targets using ribozymes and small-interfering RNAs. Methods Mol Biol 2007;361:239-63.

4. Shay JW, Wright WE. Hallmarks of telomeres in aging research. J Pathol 2007;211:114-123.

5. Nugent CI, Lundblad V. The telomerase reverse transcriptase: components and regulation. Genes Dev 1998; 12: 1073-1085.

6. Kim NW, Piatyszek MA, Prowse KR, et al. Specific association of human telomerase activity with immortal cells and cancer. Science 1994; 266: 2011-15.

7. Shay JW, Bacchetti S. A survey of telomerase activity in human cancer. Eur J Cancer 1997; 33: 787-91.

8. Saleh S, Lam A, Ho YH. Real-time PCR quantification of human telomerase reverse transcriptase (hTERT) in colorectal cancer. Pathology, 2008; 40 (in press).

9. Johnson ME, Howerth EW. Survivin: a bifunctional inhibitor of apoptosis protein. Vet Pathol 2004;41:599-607.

10. Li F, Brattain MG. Role of the survivin gene in pathophysiology. Am J Pathol 2006;169:1-10.

11. Sah NK, Khan Z, Khan GJ, Bisen PS. Structural, functional and therapeutic biology of survivin. Cancer Lett 2006;244:167-71.

12. Li F, Ling X. Survivin study: an update of "what is the next wave?” J Cell Physiol 2006;208:476-486.

13. Gerlach U, Kayser G, Walch A, Hopt U, Schulte-Monting J, Werner M, Lassmann S. Centrosome-, chromosomal-passenger- and cell-cycle-associated mRNAs are differentially regulated in the development of sporadic colorectal cancer. J Pathol. 2006;208:462-72. 
14. Lassmann S, Schuster I, Walch A, Gobel H, Jutting U, Makowiec F, Hopt U, Werner M. STAT3 mRNA and protein expression in colorectal cancer: effects on STAT3-inducible targets linked to cell survival and proliferation. J Clin Pathol. 2007;60:173-9.

15. Endoh T, Tsuji N, Asanuma K, Yagihashi A, Watanabe N. Survivin enhances telomerase activity via up-regulation of specificity protein 1- and c-Myc-mediated human telomerase reverse transcriptase gene transcription. Exp Cell Res. 2005;305:300-11

16. Cao J, Chen XP, Li WL, Xia J, Du H, Tang WB, Wang H, Chen XW, Xiao HQ, $\mathrm{Li}$ YY. Decreased fragile histidine triad expression in colorectal cancer and its association with apoptosis inhibition. World J Gastroenterol. 2007;13:1018-26.

17. Khor TO, Gul YA, Ithnin H, Seow HF. A comparative study of the expression of Wnt-1, WISP-1, survivin and cyclin-D1 in colorectal carcinoma. Int J Colorectal Dis. 2006;21:291-300.

18. Okon K, Demczuk S, Klimkowska A, Wojcik P, Osuch C, Papla B, Stachura J. Correlation of microsatellite status, proliferation, apoptotic and selected immunohistochemical markers in colorectal carcinoma studied with tissue microarray. Pol J Pathol. 2006;57:105-11.

19. Tan HY, Liu J, Wu SM, Luo HS. Expression of a novel apoptosis inhibitorsurvivin in colorectal carcinoma. World J Gastroenterol. 2005;11:4689-92.

20. Ponnelle T, Chapusot C, Martin L, Bouvier AM, Plenchette S, Faivre J, Solary E, Piard F. Cellular localisation of survivin: impact on the prognosis in colorectal cancer. J Cancer Res Clin Oncol. 2005;131:504-10.

21. Abd El-Hameed A. Survivin expression in colorectal adenocarcinoma using tissue microarray. J Egypt Natl Canc Inst. 2005;17:42-50.

22. Lin LJ, Zheng CQ, Jin Y, Ma Y, Jiang WG, Ma T. Expression of survivin protein in human colorectal carcinogenesis. World J Gastroenterol. 2003;9:974-7.

23. Agui T, McConkey DJ, Tanigawa N. Comparative study of various biological parameters, including expression of survivin, between primary and metastatic human colonic adenocarcinomas. Anticancer Res. 2002;22:1769-76.

24. Kawasaki H, Toyoda M, Shinohara H, Okuda J, Watanabe I, Yamamoto T, Tanaka K, Tenjo T, Tanigawa N. Expression of survivin correlates with apoptosis, proliferation, and angiogenesis during human colorectal tumorigenesis. Cancer. 2001;91:2026-32. 
25. Kawasaki H, Altieri DC, Lu CD, Toyoda M, Tenjo T, Tanigawa N. Inhibition of apoptosis by survivin predicts shorter survival rates in colorectal cancer. Cancer Res. 1998 Nov 15;58:5071-4.

26. Sarela AI, Scott N, Ramsdale J, Markham AF, Guillou PJ. Immunohistochemical detection of the anti-apoptosis protein, survivin, predicts survival after curative resection of stage II colorectal carcinomas. Ann Surg Oncol. 2001;8:305-10.

27. Sarela AI, Macadam RC, Farmery SM, Markham AF, Guillou PJ. Expression of the antiapoptosis gene, survivin, predicts death from recurrent colorectal carcinoma. Gut. 2000;46:645-50.

28. Chen WC, Liu Q, Fu JX, Kang SY. Expression of survivin and its significance in colorectal cancer. World J Gastroenterol. 2004;10:2886-9.

29. Hamilton SR, Vogelstein B, Kudo S, et al. Carcinoma of the colon and rectum. In: WHO Classification of Tumours: Pathology and Genetics of Tumours of Digestive System. S.R. Hamilton \& L.A. Aaltonen (eds). IARC press, Lyon (France), 2000 pp 105-119.

30. Greene FL, Page DL, Fleming ID, Fritz A, Balch CM, Haller DG, Morrow M (eds). AJCC cancer staging manual, edition 6, Springer-Verlag, Berlin/Heidelberg/New York/London/Paris/Tokyo/Hong Kong, 2002.

31. Megliorino R, Shi FD, Peng XX, Wang X, Chan EK, Tan EM, Zhang JY. Autoimmune response to anti-apoptotic protein survivin and its association with antibodies to p53 and c-myc in cancer detection. Cancer Detect Prev. 2005;29:241-8.

\section{APPENDICES}

\section{Figures legend}

Figure 1. The expression levels of survivin and telomerase in tumor are significantly higher than non-tumour mucosa.

Figure 2. The relationship between survival of patients with colorectal cancer and level of survivin mRNA showing poorer prognosis of patients with high survivin level. 